\title{
Ejercer la voz: el ensayo como estrategia narrativa en el trabajo periodístico de Martín Caparrós
}

\section{Exercising the Voice: The Essay as a Narrative Strategy in the Journalistic Work of Martín Caparrós}

\section{Gerardo Juárez Vázquez*}

RESUMEN: en este artículo se analiza el uso de métodos ensayísticos dentro de la obra periodística del autor argentino Martín Caparrós, así como las variaciones estéticas que estos usos introducen a la crónica en tanto género. Para llevar a cabo este análisis, se atiende a la dimensión histórica del ensayo, su génesis y su evolución, de manera que se haga visible la transformación que el método ensayístico genera en el tratamiento periodístico de problemas como el hambre o el cambio climático.

Palabras Clave: Crónica; Ensayo; Hambre; Cambio climático.

ABSTRACT: The article analyzes the use of essay methods in the journalistic work of the Argentine author Martín Caparrós, as well as the aesthetic variations that these uses introduce to the chronicle as a literary genre. To carry out this analysis, attention is paid to the historical dimension of the essay, its genesis and evolution, so that the transformation that the essay method generates in the journalistic treatment of problems such as hunger or climate change becomes visible.

KEY WORDS: Journalistic Chronicle, Essay, Hunger, Climate Change.

Recibido: 22 de enero de 2020

Aceptado: 24 de mayo de 2020

Posgrado en Estudios Latinoamericanos-unam (gerardo.juarez.vazquez@gmail.com). 
raíz de la publicación de la Antología personal de Ricardo Pi-
glia, Martín Caparrós dedicó en 2015 un artículo en El País a
discutir la importancia de la escritura del autor de Respiración
artificial en su vida política y artística. El texto se titula "Ser es leerse" y coloca a Piglia como el definidor de la literatura argentina contemporánea, de su canon y sus problemas. El otro trazo importante lo extiende hasta Borges:

El asunto central del fin de siglo en ese fin del mundo: cómo escribir después de Borges. Cuando muchos se esforzaban en recuperar o rechazar su retórica, su parque temático de espejos sueños laberintos, Piglia entendió que el material borgiano que servía era su mecanismo, y reformuló el cruce entre ficción y ensayo - el ensayo como ficción y viceversa- y lo volvió su matriz creativa. Así irrumpió, en plena dictadura, y refundó las cosas (Caparrós 2015).

Christian Snoey ha hecho notar (2016: 160) la importancia del artículo de Caparrós acerca de Pligia para resaltar cómo la imbricación entre ensayo y ficción se reformula y se desplaza, en el autor de El hambre, al terreno de la crónica. En este género en particular, Caparrós modula las capacidades expresivas del ensayo sin despegar la vista de la tradición de su país, con Borges y Piglia como principales impulsores y con Rodolfo Walsh como precursor del uso del género en el terreno periodístico.

La línea de variación que introduce Piglia cuando postula el mecanismo del ensayo como núcleo de su escritura de ficción (muchos de los relatos de Emilio Renzi funcionan de este modo) constituye un ejercicio que a mediados de la década de los cincuenta ya había llevado a cabo Rodolfo Walsh en los primeros compases de Operación Masacre. En este sentido, la obra de Caparrós nace de la intersección entre el trabajo de Piglia y el de Walsh, dos autores por los que ha mostrado admiración. Operación Masacre se inicia con Walsh narrando la serie de condiciones que tuvieron lugar para que la historia se pusiera en su camino: "La primera noticia sobre los fusilamientos clandestinos de junio de 1956 me llegó en forma casual, a fines de ese año, en un café de La Plata donde se jugaba al ajedrez [...]. La violencia me ha salpicado las paredes, en las ventanas 
hay agujeros de balas, he visto un coche agujereado y adentro un hombre con los sesos al aire, pero es solamente el azar lo que me ha puesto eso ante los ojos" (Walsh 2008: 7-8). El prólogo de Operación Masacre funge como una introducción ensayística al relato que vendrá después, una introducción caracterizada por la unión de la vida sensible con la vida intelectual y los compromisos que supone esta mezcla en la escritura. Walsh no fue el primero en tejer una trama periodística vertebrada por la potencia dramática de sus actores, pero sí estableció el suelo común en el que se sostienen las obras más ambiciosas de Caparrós; es decir, Walsh encontró en las historias personales el hilo para explicar las condiciones políticas de un sitio determinado en un tiempo determinado.

Este desplazamiento adquiere una particular relevancia debido al terreno desde el cual trabajaron Caparrós y Walsh: el periodismo, donde el entendido dominante desde principios del siglo xx ha sido el de perseguir una objetividad que implica la borradura de cualquier trazo del yo, sin el cual el ensayo es incapaz de existir. El ensayo, como se verá más adelante, supone el reconocimiento de las facultades interpretativas de un sujeto (qué tipo de sujeto y en qué circunstancias pueden ejercerse estas facultades son preguntas que ayudarán a una mayor comprensión del entramado del género). El periodismo busca una voz carente de cuerpo, una reproducción sin mediaciones. En el periodismo, como ha apuntado Caparrós - "La crónica, además, es el periodismo que sí dice yo. Que dice existo, estoy, yo no te engaño" (2011: 610) -, la inclusión de la característica esencial del ensayo produce un reacomodo en los límites del género.

En este artículo se analizarán las mutaciones del ensayo que tienen lugar en la obra de Martín Caparrós. Se trata de una mezcla poco común dentro del amplio espectro de trabajo periodístico que se produce en América Latina. Constituye, igualmente, un cruce fértil: introduce no sólo la capacidad del escritor para poner en práctica métodos interpretativos deudores de las ciencias sociales, sino también una forma de análisis, un posicionamiento de la mirada, en la que el ensayo acude para ayudar a la crónica en su tarea de explicar la red de relaciones debido a las cuales tienen lugar los problemas de la migración, el cambio climático y el hambre global. 
Se llevará a cabo, en primera instancia, un acercamiento al ensayo en cuanto género, a sus particularidades y a la línea desde donde se proyecta el trabajo de Caparrós. El análisis se centrará en el modo en que el escritor argentino hace resonar estas herramientas con los lugares y las personas cuyas presencias dictan el ritmo interno de Una luna, Contra el cambio y El hambre, el tríptico en el que el autor argentino intenta explicar tres de los principales problemas de la modernidad capitalista. Tras la revisión de las características formales del género, se propondrán una serie de temas alrededor de los cuales gravita el método ensayístico de aprehender la experiencia. El interés de este trabajo radica en analizar no tanto lo que en un sentido amplio estas técnicas significan, sino más bien en aquello que hacen; es decir, en la profundidad descriptiva (de los procesos pero también de las formas en que en estos contextos una persona puede experimentar sus relaciones con el entorno) que el cruce entre ensayo y crónica posibilitan en la escritura de Caparrós.

\section{EL PROBLEMA DE LA VOZ}

El ensayo, en cualquiera de sus configuraciones históricas, constituye una bisagra entre la experiencia y el sentido. Su riqueza proviene de la enorme complejidad en el tránsito entre una y otro. Como dice Liliana Weinberg, "el juicio es un enlace entre mi forma de experimentar y tratar de entender la forma en que el mundo se da a mí, con el sentido general. Esto explica que el ensayo sea íntimo, privado, a la vez que público y social" (Garza 2007: 286). Para llevar a cabo esta tarea, el ensayo ha debido alimentarse de distintas formas discursivas. Paz lo describió enfatizando en sus capacidades maleables destinadas a aprehender la experiencia: "En uno de sus extremos colinda con el tratado; en el otro, con el aforismo, la sentencia, la máxima" (Weinberg 2007: 191). La maleabilidad del ensayo se explica por el campo de acción en el que opera, interesado en la unión entre la vida sensible y el juicio intelectual. 
Para entender esta imbricación, habría que llevar a cabo un recorrido por los orígenes históricos del género. "El ensayo, por supuesto, nació como experimento. Un experimento muy francés - con Montaigne, con Rousseau, con Diderot-sometido a la presión autobiográfica y a las teorías de los humores" (Carrión 2014: 1). Montaigne inaugura el género teniendo como horizonte la ligazón entre experiencia y sentido; abre también la posibilidad de postular la propia experiencia como objeto de conocimiento: "La experiencia vivida se vuelve memoria y sentido, a través del esfuerzo mismo por participarla: un viaje a la semilla que es, en un extremo, totalmente personal, y en el otro, absolutamente humano. No hay aquí anécdota sino necesidad; no hay aquí dato ciego sino experiencia vivida; no hay un presente impersonal y monocorde: hay un tiempo que, de tanto vivirlo, se torna a la vez memora e imaginación" (Weinberg 2001: 31).

Es necesario estudiar cómo, tras la primera configuración francesa, la noción de ensayo adquirió cierta estabilidad. Pedro Aullón de Haro, sin soslayar las genealogías extensas y complicadas del género, lo describe como el producto de dos principios fundamentales en las resoluciones de la cultura de la modernidad:

Esto es, por una parte la integración de contrarios u opuestos establecida por el Romanticismo, la cual explica de hecho, como hibridación o entremezclamiento, el conjunto de posibilidades realizativas de la nueva Literatura, desde, por ejemplo, la polimetría a la tragicomedia; por otra parte, la caída de la causa final clasicista que había restituido el pedagogismo moral neoclásico, es decir la anulación del finalismo extraartístico y el consiguiente dominio de la libertad kantiana, tanto ética como estética. Esos dos principios son la condición para la estable y caracterizada creación moderna del Ensayo. Para un encuentro de arte y pensamiento (Aullón 1997: 170).

El encuentro entre arte y pensamiento del que habla Aullón está ligado a la conquista del presente que menciona Weinberg, para quien el ensayo representa "la vivencia sentimental de una experiencia intelectual" (2007: 150). Se trata, según la autora, de dar resolución estética a problemas epistémicos o éticos; es decir, "una puesta en el presente vivo del acto de pensar y de representar el mundo" (Garza 2007: 282). 
En este sentido, el ensayo posibilita proyectar la experiencia al mundo con la esperanza de llevar a cabo una apertura: "El ensayo no sólo es reflexión sobre los valores sino, más aún, "apertura a la experiencia ajena" y "mediación de normas" a través de una dotación de forma, a la vez que, en cuanto obra de arte, es también despliegue de una capacidad fundadora y configuradora de normas, según Jauss" (Weinberg 2006: 50). El género, en suma, permite utilizar el vínculo entre experiencia y sentido como manera de abrir otras formas de visibilidad: "El ensayo aparece bajo nueva luz, como bisagra entre la historia y la reflexión, como punto de inflexión de teoría y praxis: no como remplazo de la praxis, sino como lugar en el cual la praxis se reflexiona y se relanza a sí misma" (Cerutti 2009: 114).

En Situación del ensayo Weinberg menciona que:

la interpretación es constante confrontación del plano semiótico con una realidad extrasemiótica, el ensayo es el género por excelencia para llevar a cabo el proceso interpretativo, y más aún, el ensayo se constituye en interpretación de interpretaciones y representaciones simbólicas y conceptuales ya dadas por el contexto y la tradición cultural en que está inmerso (2006: 23).

El ensayo como género no existe por fuera de las jerarquías propias del sistema cultural en el que se pone en práctica. Se trata, en esencia, del lugar que ocupan unos y otros dentro de la estructura donde estas voces ocurren. En el prefacio a Can Non-Europeans Think? Hamid Dabashi (2016) se refiere a la dificultad de ciertos filósofos europeos para colocarse en el mismo espacio epistémico que otros pensadores no europeos.

These philosophers cannot comprehend the notion of the moment when a thinker might actually not be talking to them, but rather be standing right next to them, neither under nor over them, nor indeed up there. They are blinded to the world in which other people think their unthinkable thoughts. When their anthropologists and area specialists read the world for them, they assimilate this reading into what they already know; and what they know is how to rule, how to own, how to possess (2016: 19). ${ }^{1}$

1 Estos filósofos no pueden comprender el hecho de que un pensador pueda no estar hablándoles directamente a ellos, en el mismo plano, no arriba ni abajo. Se han cerrado a un mundo en el que otras personas formulan pensamientos inéditos. Cuando 
Dabashi continua diciendo que el conjunto de conocimientos en la época actual se encuentra en una etapa de transición cuyo objetivo consiste no en acercarse al poder, sino en resistirse a formar parte de sus canales de transmisión. Una vez que se ha llevado a cabo esta fractura, argumenta Dabashi, se habrá abierto la posibilidad de efectuar otro tipo de lecturas: "If they read Shamlou they will understand Heidegger on Rilke better, and if they learn Darwish they will understand Langston Hughes, James Baldwin and C.L.R. James in a wholly different light" (Dabashi 2016: 16). ${ }^{2}$ La fractura de la que habla Dabashi en el terreno teórico ocurre también en el análisis que hace Caparrós sobre los problemas que aparecen en su obra, un análisis que se resiste a participar en los canales de transmisión del poder al leer sus causas desde una tradición poco visitada por el discurso dominante. En este punto nos encontramos con uno de los problemas centrales que vertebran este análisis: la imbricación entre el trabajo de Caparrós y los lugares de enunciación a los que nos remiten los géneros presentes en sus narraciones.

El ensayo constituye uno de los pilares básicos del proyecto moderno. Supone la idea de una comunidad de iguales a través de cuya puesta en práctica del juicio - de la capacidad de juzgar - tiene lugar la cultura. No es ninguna coincidencia la elección de palabras de Montaigne al otorgar nombre al género: "Es el juicio un instrumento necesario en el examen de toda clase de asuntos, por eso yo lo ejercito en toda ocasión en estos Ensayos" (Aullón 1997: 171).

En esta forma de organización, el diálogo que pone en movimiento el ensayo funciona como la prueba de la salud de una comunidad.

The ideal of conversation as the activity most befitting a civil society was given its modern elaboration in the Italian city-states of the Renaissance,

sus antropólogos y especialistas de la zona leen el mundo para ellos, encapsulan ese conocimiento con los parámetros que ya conocen; lo que conocen es cómo dictar, cómo apoderarse, cómo poseer [traducción del autor].

2 Si leyeran a Shamlou, entenderían mejor a Heidegger o a Rilke; si entendieran a Darwish, verían a Langston Hughes, James Baldwin y C. L. R. James de una manera completamente distinta [traducción del autor]. 
and a classical formulation in Stefano Guazzo's, La civile conversatione [...] Indeed, there must still be those who cling to the notion that "the English-speaking peoples" have a claim to the one genuine civil conversation, to a commonwealth of discourse (Bohm 2000: 1). ${ }^{3}$

La capacidad de juzgar se ha considerado en el pensamiento occidental una de las formas básicas de crear comunidad. En su tercera crítica, Kant otorgaba a este acto el privilegio de construir un grupo de iguales a través de cuya puesta en práctica del juicio, como encontró Hannah Arendt en su lectura de la crítica kantiana, "podrían encontrarse estrategias creadoras de comunicación, de sentir común" (Rivera 2005: 7). Para Arendt el segundo vínculo radica "en que la facultad de juzgar se ocupa de particulares, que 'como tales, en consideración a lo universal, encierran algo contingente', y lo universal normalmente es aquello con lo que opera el pensamiento" (Arendt 2003: 33). El diálogo entre iguales constituyó una de las imágenes propias de una sociedad civilizada. No obstante, el grupo de iguales en el que pensaba Kant se refería a las sociedades europeas que formaban el centro del poder colonial. Sin embargo, en el desplazamiento del centro a los márgenes colonizados la libertad para hablar sufrió una transformación. Se convirtió, como anota Bohm (2000), en una exigencia de palabras. En lugar de una conversación entre iguales, el diálogo en un contexto colonial está mediado por las relaciones de poder incorporadas en los hablantes. El diálogo, aquí, reafirma en todo momento la desigual distribución de posibilidades entre colonizador y colonizado.

Bohm hace notar la enorme importancia de la tecnología en la configuración de la idea de diálogo: "This is the introduction of technology into the system. The demands put by technology to the world transform the conditions for all conversation, for technology's mode is merely inter-

3 La idea de la conversación como una actividad propia de la sociedad tomó su forma actual en las ciudades-estado italianas del Renacimiento, y su formulación clásica, en La conversación civil de Stefano Guazzo [...] En efecto, todavía existen aquellos que se aferran a la noción de que los hablantes de lengua inglesa son los dueños e inventores del discurso civil [traducción del autor). 
rogative" (Bohm 2000: 7). ${ }^{4}$ El diálogo entre colonizador y colonizado se ve condicionado por el modelo de extracción dominante en la relación imperio-colonia. Esto podría parecer una sobreinterpretación, el traslado del funcionamiento industrial a la dinámica puesta en práctica por los hablantes, pero numerosos teóricos han analizado cómo el uso de la técnica determina el modo en que establecemos contacto con el mundo. Groys lo describe así: "Este diálogo es regulado por la forma en que definimos las preguntas válidas que dirigimos al mundo o que el mundo nos dirige, y por los modos en que podemos identificar las respuestas relevantes a esas preguntas" (2014: 193).

De este modo, el problema de la voz, central en el análisis del género ensayístico, se muestra en su complejidad. Siguiendo esta lógica, territorio y sujeto colonial son concebidos como sitios de extracción (de recursos, de respuestas). El modelo de conocimiento desprendido del uso de la técnica se aplica también a los hablantes. Concebirse como parte de una comunidad de iguales, como se pretendía en los orígenes franceses del género, resulta una entelequia cuando las condiciones para el ejercicio del juicio no son las mismas para todos los practicantes. Para los sujetos colonizados, cualquier intento de hacer oír su voz se ve interrumpido por el código de la tecnología según el cual toda respuesta es también una extracción.

Esta idea adquiere especial importancia poniéndola en tensión con los trabajos de Caparrós, en especial en Contra el cambio, donde los discursos contra el cambio climático oscurecen los procesos de extracción propios de las empresas coloniales:

Los países centrales ya hicieron su conquista de la naturaleza, su desarrollo sucio. Y el mundo está como está porque ellos lo hicieron, pero ahora se dedican a dictar normas a los países más pobres sobre cómo proteger esa naturaleza que ellos ya se cargaron: cómo seguir siendo pobres pero verdes. Digo: es como un chiste que los grandes impulsores de la ecología

Aquí se introduce la tecnología dentro del sistema. Las exigencias que la tecnología dirige al mundo transforman las condiciones de la conversación, pues la esencia de la tecnología opera a partir de la interrogación [traducción del autor]. 
sean las sociedades que ya cambiaron sus ecosistemas hace tres, cinco, dos siglos para adaptarlos a sus necesidades y apetitos - y que sacaron de todo eso pingües beneficios. Ahora quieren que los otros, los pobres, respeten lo que ellos no respetaron, so capa de "salvar al planeta". Esa es, ahora, una de las claves del debate (2010: 40).

El problema es complejo y Contra el cambio no pretende despojarlo de sus tensiones. Por ello lo piensa a partir de la experiencia de Fátima, una estudiante nigeriana que participó en un programa de intercambio del gobierno británico gracias al cual pasó tres meses en Birmingham. De acuerdo con Caparrós, Fátima pertenece a la generación de jóvenes que encuentra en el entramado de las oenegés una manera de sentir que hacen algo por el mundo y por sí mismos: "Para Fátima - para millones de Fátimas-, sus actividades son un modo de afirmar un lugar en el mundo [...] Fátima no habría salido de su pueblo todavía, no habría llegado hasta Inglaterra, no estaría tramitando su visa para ir a un curso de quince días sobre salud reproductiva en Estocolmo, no usaría una computadora" (2010: 62).

En este contexto, la aparición de estas oportunidades no es sino otro nodo en la red del problema. El discurso contra el cambio climático es también otro nodo. La magnitud de la red se hace visible cuando Fátima dice que en uno de los encuentros del intercambio supo del calentamiento global provocado por las emisiones de carbono. "En mi casa yo cocino con leña, y ni siquiera sabía que estaba causando un daño a mí mismo y al resto del mundo, por la tala de árboles y las emisiones de co2" (2010: 64). La relación entre los fogones para cocinar con leña y el cambio climático fue puesta en circulación en un artículo del New York Times (citado en Contra el cambio) según el cual el reemplazo de los fogones por versiones más modernas ayudaría a reducir el nivel de polución global. El New York Times no lo proponía como una solución, pero sí lo consideraba un paliativo mientras los países desarrollaban tecnologías para disminuir las emisiones de carbono provenientes de los combustibles fósiles.

"Supongo que tiene sentido", escribe Caparrós (2010: 64), "pero parece un chiste: frente a los gases de cualquier central térmica norteamericana, frente a los cuarenta millones de coches de Alemania, frente 
a miles de aviones todo el tiempo en el aire, el aporte del hollín de los fogones africanos o asiáticos es de una modestia espeluznante". Más aún, continúa Caparrós, el uso de los fogones para cocinar con leña produce enfermedades pulmonares que matan, cada año, a más de un millón y medio de personas, además del hecho de que los fogones son usados por los segmentos de población de menores recursos. Estos dos datos no aparecen en el artículo del New York Times, del mismo modo que no aparece en los discursos dominantes sobre el cambio climático que le fueron transmitidos a Fátima.

"Son actividades que se basan en la pequeña mejora, en la reforma. No pretenden cambiar el mundo, o las ideas fundamentales de ese mundo", escribe Caparrós (2010: 62) sobre las acciones de organizaciones como aquélla en la que participa Fátima, actos de cuyas intenciones difícilmente se podría dudar (¿quién podría estar a favor del calentamiento global?) pero que cumplen con la función de eliminar del sistema de representaciones las diferentes formas de desigualdad que también forman parte del problema. De este modo, estos discursos configuran los márgenes dentro de los cuales tienen valor las expresiones en contra del cambio climático. Establecen un lenguaje; instituyen jerarquías en el proceso de enunciación: "Fátima sonríe cuando habla. Yo también cuando la escucho, porque nunca deja de sorprenderme la facilidad con que ciertas palabras de la tribu global se deslizan en las bocas más variadas: cuántas personas hay, en todas partes, que se dejan hablar por el idioma oenegero" (Caparós 2010: 61).

Por este motivo, el ensayo contribuye en la obra de Caparrós al desafío de las representaciones. Lo hace enfrentándose al mismo tiempo al problema de la voz como extracción según lo vimos con el modelo tecnológico que opera en todo sistema colonial. Como argumenta Mateo (2018: 85) en relación con la actividad intelectual y política de Revueltas, uno de los efectos de la obra de Caparrós consiste en "una permanente deconstrucción del sentido y una continua rearticulación de los medios para pensar el mundo". Esta tensión se intensifica con los cruces que tienen lugar en la obra del autor argentino. 
HISTORIA DE LOS AFECTOS

Lo que hasta ahora se han delineado han sido los modos a través de los cuales la escritura de Caparrós describe ciertos procesos económicos y cómo éstos funcionan en determinados contextos. Para esta tarea, las capacidades analíticas del ensayo permiten mostrar las fuerzas, los marcos y las lógicas que operan dentro de los discursos que sostienen estas transformaciones. El alcance de las obras, sin embargo, se extiende hasta los cambios que estos procesos provocan en las relaciones humanas. En este apartado, en consecuencia, se llevará a cabo lo que Derek Attridge ha llamado, en traducción propia, una lectura encarnada:5 "A Reading that occurs as an event, a living-through or performing of the text that responds simultaneously to what is said, the way which it is said, and the inventiveness and singularity (if there is any) of the saying" (Attridge 2004: 60). ${ }^{6}$

La lectura por la que aboga Attridge se acerca a la noción de interpretación más en un sentido teatral que exegético: un ejercicio de prestar cuerpo a las voces presentes en la obra. Se trata de una herramienta de acercamiento al texto mediante la cual se intenta captar la cualidad específica de la experiencia individual, una apertura a la presencia de los otros en el trabajo literario. No hay nada nuevo en este tipo de lectura, señala Attridge (2004: 60): es la forma más básica, quizás ingenua, de interactuar con un trabajo literario. Los niños lo hacen al oír una historia. Lo que otorga, sin embargo, es una resistencia a la alegorización, a privilegiar los imperativos del comentario literario por encima de la experiencia di-

5 Literal Reading, lo llama Attridge (2004: 60). La traducción de lectura encarnada parece, en este contexto, más adecuada que lectura literal o, como podría traducirse otra noción propuesta más adelante por Attridge, lectura literaria. Ni una ni otra ofrecen el contacto cercano implícito en el concepto; por el contrario, dan la impresión de colocar una mediación infranqueable entre el texto y la lectura: "I can, one might say, live the text that I read. This is what I mean by literal reading" (2004: 40). "Puedo, se podría decir, vivir el texto que leí. Esto es lo que quiero decir con lectura literal" (traducción del editor).

6 "Una lectura que se produce como un evento, una vida o realización del texto que responde simultáneamente a lo que se dice, la forma en que se dice, además de la inventiva y singularidad (si la hay) del decir" (traducción del editor). 
recta con el texto. La lectura encarnada permite acercarse al cuestionamiento de lo que significa ser humano en determinadas circunstancias.

La importancia de efectuar esta lectura en relación con el trabajo de Caparrós radica en que hace visibles los nuevos procesos de socialización que resultan de la agudización de problemas que se han presentado en las últimas décadas. El reajuste de condiciones económicas y sociales produce también otras formas de vinculación. En este sentido, la obra de Caparrós se acerca a aquello que Svetlana Alexiévich menciona en Los muchachos del zinc: "Yo rastreo el sentimiento, no el suceso. Cómo se desarrollan nuestros sentimientos, no los hechos. Probablemente lo que yo estoy haciendo se parece a la labor de un historiador, soy una historiadora de lo etéreo" (2016: 29).

Esta historización de lo etéreo, como lo llama Alexiévich, constituye también conocimiento. Tradicionalmente, ha sido la literatura la que se ha encargado de preservar y transmitir con un alto grado de profundidad la calidad de la experiencia durante determinados momentos históricos: acudimos a Balzac para entender las formas de interacción presentes en determinados grupos durante algunas décadas del siglo XIX francés, así como la lectura de Campobello nos ofrece una imagen de los afectos que circularon en los años posteriores a la Revolución mexicana. Este es uno de los fenómenos que, de acuerdo con Salazar (2005), han permitido a la crónica tener mayor relevancia en la discusión sobre las formas narrativas culturalmente validadas. Para Salazar, nos encontramos en una época "en la cual dejar testimonio de los distintos regímenes de terror que se vivieron en el siglo xx adquiere gran importancia, ante la necesidad ética de construir una cultura crítica que impida que esa violencia extrema se repita". El testimonio entonces aparece dentro del ensayo y el periodismo contemporáneo como una herramienta de reconstrucción.

Es esta fugacidad del aparecer la que motiva algunas de las partes más potentes de la obra de Caparrós. El hambre empieza con el choque de la mirada del autor con tres mujeres en Níger, quienes en un hospital juntan con lentitud sus platos de plástico y su olla tiznada. "Pero me quebré cuando vi que la tía se inclinaba sobre el catre", escribe Caparrós, "levantaba al 
chiquito, lo sostenía en el aire, lo miraba con una cara rara, como extrañada, como incrédula, lo apoyaba a espaldas de su madre como se apoyan los chiquitos en África en las espaldas de sus madres [.. . ] El chiquito quedó en su lugar, listo para irse a casa, igual que siempre, muerto" (2014: 9).

El germen del libro está anclado al momento emocional en el que Caparrós entiende el desfase entre su sistema de representaciones y el modo en que se expresa en un grupo social cuyo desarrollo no ha existido por fuera de una condición de hambre estructural. "El hambre es, en mis imágenes más viejas, un chico con la panza hinchada y las piernas flaquitas en un lugar desconocido que por entonces se llamaba Biafra" (Caparrós 2014: 11). El hambre como condición vital crea una atmósfera de normalidad que se ubica en el lado opuesto de las imágenes con las que tradicionalmente se la ha representado: imágenes como la que menciona Caparrós (otro ejemplo sería la fotografía de Kevin Carter de un niño sudanés siendo visto por un buitre) circulan como prueba de un estado de crisis, como la demostración del fallo del sistema, cuando lo que hace notar Caparrós es que éstas no son sino su prolongación.

Más tarde, Caparrós sabrá que la actitud de las mujeres de Níger mantiene una estrecha relación con la noción de maternidad que opera en el país. La maternidad se entrecruza con otros dos aspectos. Por un lado, la alta tasa de natalidad en Níger suele analizarse como una de las razones por las cuales se explica la crisis de hambre en el país: más bocas para el poco alimento. En relación con este argumento, Caparrós estudia el núcleo cristiano presente en la teoría de Thomas Maltus, uno de los más influyentes pensadores sobre el problema del hambre, para quien la sobrepoblación termina siendo regulada por las hambrunas, las enfermedades o las reglas. De acuerdo con Maltus, el hambre también cumplía con la labor de espolear a los pobres al trabajo: "Una cosa es bajar la tasa de natalidad de un país repleto; otra muy distinta es convencer a sus más pobres de que la responsabilidad de su pobreza es suya - porque tienen demasiados hijos. Malthus, en bengalí, se dice Malthus" (Caparrós 2014: 237).

El hecho de que las mujeres de Níger se hayan marchado con el hijo muerto a las espaldas se explica por el estado de normalidad que 
ha creado el problema del hambre. No se trata de que la muerte haya perdido su peso; por el contrario, lo que se acentúa es la dependencia y la vulnerabilidad que existe dentro de una familia (la familia, en situaciones así, ha reemplazado al Estado como esa entidad encargada de ofrecer las condiciones básicas para el desarrollo de una vida). En este sentido, al hablar con integrantes de Médicos Sin Fronteras Caparrós encuentra que muchas de las mujeres de Níger no pueden dedicar más de uno o dos días al cuidado de un hijo en el hospital, pues eso supondría descuidar a los demás, laborar una jornada menos, ser incapaz de llevar alimento al resto de la familia. El duelo no ha desaparecido, sino que se ha adecuado a las exigencias del entorno.

El alto índice de natalidad adquiere otro significado cuando se tienen en cuenta estas exigencias. Si en el sistema de representaciones de cualquier país con condiciones menos adversas un hijo supone una promesa de permanecer (permanencia genética, física, nominal), en lugares como Níger un hijo implica la posibilidad de ser cuidado al llegar a la vejez, de manera que al aumentar los hijos aumentan las posibilidades. Una vez más, no se trata de que los vínculos familiares se hayan deteriorado: sólo ocurre que en estas condiciones vitales ideas como futuro o descendencia han adquirido otro peso; la mirada se ha transformado. Los afectos continúan siendo puestos en marcha, pero ahora ejercen su influencia de otras maneras.

Estas tensiones configuran la vida de Shallala, una mujer de Daca a quien Caparrós conoce cuando ella está esperando a uno de sus hijos afuera de un hospital. Cuando la encuentra, a Shallala los doctores de Médicos Sin Fronteras acaban de decirle que el hambre que ella y sus hijos padecen es también una enfermedad. Esta información pone en perspectiva aquello que hasta el momento había entendido por normalidad. "Ahora cada vez que no como pienso qué me estará haciendo por dentro, dice Shallala. Pero, todavía más que el hambre, es costumbre la malnutrición: cómo decirles que esos alimentos repetidos, pobres [...] que ellos y sus padres y sus hijos han comido siempre no alcanzan para nada, no sirven 
para hacer hombres y mujeres fuertes, capaces de vivir vidas en serio" (Caparrós 2014: 250).

La frustración de Shallala se agudiza cuando se percata de que la cantidad de horas de trabajo que necesita para llevar un poco de arroz a casa no ha sido suficiente.

A Shallala sus hijos le importan más que nada, y ahora está preocupada: ella sabía que si no comían lo pasaban mal pero creía que si al final comían no pasaba más nada, y una médica sin fronteras le acaba de decir que no es así, que si sus hijos siguen mal van a tener muchos problemas cuando crezcan porque van a crecer menos y a aprender menos, dice, y que eso le dolió porque ella tendría que haber hecho otra cosa, dice, ser capaz de darles lo que necesitan, dice, una lágrima sola (Caparrós 2014: 251).

Shallala reacciona con pesar y culpa, pero no siempre sucede así. Muchas mujeres se ofenden, se aterran, se deprimen. En última instancia, argumenta Caparrós, cuando reciben la noticia de que sus hijos no han comido lo suficiente están, al mismo tiempo, siendo informadas de que no han cumplido su labor como madres: "Yo siempre les digo a las enfermeras que tengan mucho cuidado en cómo se lo dicen, me dirá una mañana Astrid, la noruega coordinadora de enfermeras. Sobre todo, que no parezca que les estamos reprochando nada. Pobres mujeres, encima de todo que no parezca que les decimos que ellas tienen la culpa" (2014: 251). De este encuentro, Caparrós concluye que existe una enorme diferencia entre el hambre en su expresión más bruta (el niño en la fotografía de Kevin Carter) y la malnutrición como constante vital, y esa diferencia radica en la conciencia de la propia condición. Resultaría grosero decir a alguien disminuido por la hambruna que su padecimiento pudo haberse evitado. Con la malnutrición, que ancla su peso en los hábitos transmitidos entre generaciones, esta labor exige considerar las dificultades del lugar de enunciación.

La labor de cuidado que se ve transformada en un contexto de hambre estructural se extiende también a las relaciones entre géneros y la forma en que éstos entienden su posición. En este punto, Caparrós sigue la línea trazada por el análisis que Federici hace de la transición europea 
hacia el capitalismo: "La 'feminización de la pobreza' que ha acompañado la difusión de la globalización adquiere un nuevo significado cuando recordamos que este fue el primer efecto del desarrollo del capitalismo sobre las vidas de las mujeres" (Federici 2005: 37).

La conciencia de esta feminización de la pobreza aparece en el trabajo de Caparrós cuando después de hablar con una docena de mujeres, pocas de ellas pueden responder a la pregunta de qué hacen en su tiempo libre. El trabajo de reproducción y cuidado de la vida ocupa toda su existencia. No hay nada por fuera de este modelo cuyas consecuencias recaen, de igual modo, principalmente en las mujeres (recordando las recomendaciones de la Organización Mundial de la Salud sobre los fogones para cocinar con leña, Caparrós recuerda que la mayor parte de las víctimas de enfermedades pulmonares son mujeres).

A veces parece como si el hambre fuera cosa de mujeres. Si yo fuera un etimólogo o etimologista o entomólogo, querría saber si hay raíces comunes entre esas dos palabras tan comunes, tan cercanas: hambre y hembra. O faim y femme, o fame y fémina [...] Y parece como si el hambre fuera sobre todo cosa de mujeres: lo tienen más cerca, lo sufren cuando cocinan, lo sufren en sus hijos, lo sufren cuando los llevan al hospital y sus hombres no, lo sufren cuando sus hombres sí comen y ellas no, lo sufren, queda dicho: el 60 por ciento de los hambrientos en el mundo son mujeres (Caparrós 2014: 235).

Todo esto ocurre a pesar de que en las últimas décadas muchos de los países afectados por el hambre extrema han sido gobernados por mujeres (India, Pakistán, Sri Lanka, Indonesia); es decir, las fuentes del problema no radican en quién ejerce las facultades de cierta posición (en este caso la presidencia) sino en el sistema que determina la lógica de la repartición de los recursos.

Ahora bien, el hecho de que pueda hablarse de una feminización de la pobreza no oscurece las particularidades de las relaciones entre hombres y mujeres en este contexto. En una existencia estructurada por la búsqueda del alimento del día, mujeres y hombres encuentran muy poco espacio para desviarse de los papeles tradicionales que les ha asignado 
un buen número de culturas: la mujer ejerce la labor de reproducción y cuidado de la vida, mientras que el hombre se encarga de fungir como proveedor. Sin las condiciones necesarias para cumplir con estas tareas (Shallala incapaz de asegurar el bienestar de sus hijos, su esposo incapaz de llevar alimento a casa), hombres y mujeres fracasan:

En Níger la agricultura, el sustento de nueve de cada diez personas, es una actividad para los hombres: las mujeres hacen sus esfuerzos, intentan cosas, pero todos saben que los que deben alimentar a la familia son los hombres $[\ldots]$ En sociedades opulentas romper con esa idea puede ser más fácil, más factible; en mundos como éste se complica. Y, aquí, no debe ser sencillo ser un hombre: tener que proveer y no tener, fallar constantemente (Caparrós 2010: 103).

¿Cuál es el resultado de este fracaso? Inmersos en un sistema que no les permite llevar a cabo las tareas tradicionalmente asignadas a sus géneros, las tensiones entre mujeres y hombres, presentes en casi todas las culturas, se exacerban. La violencia se convierte en la única estrategia efectiva para sostener esta división jerárquica de géneros. En los libros de Caparrós las mujeres continuamente hablan de cómo sus esposos las golpean, pero esto no siempre deviene en un pacto de sumisión. Del mismo modo, las posiciones de poder no se mantienen fijas, si bien por lo regular es el hombre el que tiene la opción de dejar a la familia y deshacerse de la responsabilidad. Fatema, por ejemplo, dice que su esposo la golpeaba cuando el dinero que ella traía no le parecía suficiente. Él apenas trabajaba. Después de un tiempo se marchó de casa.

¿Querrías que volviera? Fatema vacila. Piensa mucho para decir que al fin y al cabo no le cambia nada que esté o no esté: que igual ella tiene que ganar la plata para dar de comer a sus dos hijos. Su hija tiene fiebre: duerme sobre su falda, las dos en el suelo de tablas de su cuarto. ¿Pero no te molesta vivir así, quedarte sola? No, prefiero. Casi siempre prefiero. Un hombre tiene que ocuparse de su familia; si no, no es un hombre (Caparrós 2014: 252). 
En última instancia, lo que transforma con mayor fuerza el estado de hambre extrema en el que se desarrollan las personas que aparecen en la obra de Caparrós tiene que ver con la idea de futuro. "Comer es escribirse, estructurarse: cada pueblo escribe su relato de sí mismo cada día con las comidas que come, con la forma en que las come, el modo en que las piensa, las recuerda, las desea" (2014: 244). En las comunidades de Níger, de Delhi o en los basurales de Buenos Aires, el relato estructurado por la comida se construye con una monotonía (arroz, bolas de mijo) y una precariedad que hace girar en torno a sí mismo el resto de actividades y afectos. La existencia material transforma la vida imaginativa; de ahí las mujeres que no entienden la noción de tiempo libre o la chica nigerina cuyo mayor anhelo consiste en poseer dos vacas. El futuro, determinado por las condiciones necesarias para el desarrollo de una vida digna, pasa de ser una categoría temporal a convertirse en una política: "La zozobra de ganarse la vida cada día. La ecuación es muy simple: no hay reservas. Si hoy consigue plata, su familia y él comen; si no, no. Y mañana, y pasado. Hay que salir y ver, y puede ser y puede no ser. La idea de reserva, de ahorro, de garantía - que fundó culturas, que constituye la nuestra- no existe: hay que salir y ver y puede ser y puede no ser" (2014: 231).

\section{LLANTO GLOBAL, EL MAYOR DE LOS PRIVILEGIOS}

Si hay una cuerda que tensa y que al mismo tiempo une los temas propuestos en la escritura ensayística de Caparrós, ésta sería la sostenida por la pregunta en relación con la vida y los márgenes dentro de los cuales ésta es reconocida. La imagen que se desprende de la lectura conjunta de $E l$ hambre, Contra el cambio y Una luna deviene en un cuestionamiento sobre las posibilidades de la representación, la disposición del trabajo y la manera en que los cuerpos actúan y son codificados en un contexto económico que está a punto de llegar a la saturación.

"Cuando analizamos los modos más comunes de pensar la humanización y la deshumanización, partimos del supuesto de que los que gozan 
de representación, especialmente de autorrepresentación, tienen más probabilidades de ser humanizados, y quienes no tienen la oportunidad de representarse corren mayores riesgos de ser tratado como menos que humanos, considerados menos que humanos, o directamente no tomados en cuenta", escribe Butler (2006: 176). Esta observación de Butler es uno de los polos en torno a los cuales gravita Una luna, en la que Caparrós entrevista principalmente a migrantes provenientes del centro y el norte africano residentes en países europeos. Las entrevistas tienen lugar entre 2008 y 2010, cuando la crisis de migración empezaba a presentarse; es decir, los rostros ${ }^{7}$ de estas personas ya aparecían con regularidad en los medios de comunicación. "Parece que la personificación no siempre humaniza", acota Butler (2006: 177) y lo reafirma Koné, el chico de Costa de Marfil radicado en Barcelona, cuando deposita su esperanza en que el texto de Caparrós pueda ayudarlo: "Koné estaba ilusionado con que la publicación podría ayudarlo a conseguir el asilo -y yo también lo creía. Creo que incluso se lo dije, antes de que me lo contara, cuando estaba dudando. Le dije que contarme su vida podría servirle para algo" (2009: 113). Koné cree que la difusión de su historia tendrá más repercusión que cualquier otra cosa que él pueda hacer. Sabe que miles como él han sido objetos de representación, pero confía en que su historia individual lo separe del resto. Parece que en ningún momento se le ocurre que él podría hacerse cargo de su propia representación: no cuenta con las características (políticas, económicas) para que su voz circule.

"Sin embargo, la eliminación de lo humano de los medios a través de la imagen tiene que ser pensada en los términos de un problema más amplio - a saber, el de los esquemas normativos de inteligibilidad que establecen lo que va ser y no va a ser humano, lo que es una vida vivible y una muerte lamentable-" (Butler 2006: 182). El problema entonces se desplaza hacia la representación mediática (de la cual las obras de Capa-

Butler discute a profundidad la concepción levinasiana del rostro, según la cual el rostro del Otro nos exige una demanda ética, nos formula el discurso no matarás, y es en ese intercambio entre rostro y mirada que nos volvemos responsables de la precariedad del Otro (2006: 165-176). 
rrós sin duda forman parte) que marca los límites dentro de los cuales una vida conserva el privilegio del duelo, aquello que Butler, en la expansión de estas ideas publicada cuatro años más tarde, llama las vidas lloradas (2010):

Cuando leemos noticias sobre vidas perdidas, a menudo se nos dan cifras; pero éstas se repiten cada día, y la repetición parece interminable, irremediable. Así, tenemos que preguntarnos, ¿qué se necesitaría no sólo para aprehender el carácter precario de las vidas perdidas en el transcurso de la guerra, sino, también, para hacer que dicha aprehensión coincida con una oposición ética y política a las pérdidas que la guerra acarrea? Entre las preguntas que surgen de este planteamiento, podemos citar dos: icómo consigue producir afecto esta estructura del marco? y icuál es la relación entre el afecto y un juicio y una práctica de índole ética y política? Afirmar que una vida es precaria exige no sólo que una vida sea aprehendida como vida, sino también que la precariedad sea un aspecto de lo que es aprehendido en lo que tiene de vida (2010: 29).

Butler escribe en el contexto de los conflictos desatados por Estados Unidos en Medio Oriente en los primeros años del siglo xxI. De este acontecimiento histórico se desprende que Butler siga pensando en términos de situaciones extraordinarias (en este caso la guerra). Lo que plantea Caparrós en su trilogía es, por el contrario, la narración de un estado de las cosas, un estado que sin estar exento de resistencias se ha normalizado: "Son muertes que no salen en los diarios. No podrían: colapsarían los diarios. En los diarios sale lo inhabitual, lo extraordinario (2014: 23). Al igual que Butler, Caparrós comparte su preocupación por la despersonalización inherente de trabajar con cifras. De hecho, la leyenda que aparece al reverso de la edición de El hambre reproduce un fragmento en el que se habla de la cantidad de personas que mueren de hambre cada hora. Estas tensiones se convierten en uno de los focos principales del libro: ¿cómo hablar de este problema sin caer en ese proceso de despersonalización? (si fuera más valiente, escribiría este libro sin usar una sola estadística, escribe Caparrós al inicio de la obra). Y quizá más importante desde un punto de vista periodístico, político y crítico: ¿qué se esconde detrás de la arbitrariedad de esas estadísticas? ¿A qué intereses responden?: 
La FAO consiguió una reducción importante de la cantidad de desnutridos en el mundo -con un cambio en la metodología de sus cálculos. Ya lo habían hecho otras veces [...] En 1990 la FAO revisó todos sus cálculos anteriores. Dijo que el método estadístico que habían usado estaba mal y que ahora sabían que en 1970 no había 460 millones de hambrientos sino más del doble: 949 millones. Lo cual les permitía decir que los 786 millones de ese momento -1990 - no suponían un aumento del hambre sino un retroceso: un gran logro (2014: 111).

Para Butler, la vía para abrir otras formas sensibles pasa por "establecer modos públicos de mirar y escuchar que puedan responder al grito de lo humano dentro de la esfera visual - una esfera en la que la huella del dolor se ha inflado hiperbólicamente para justificar un nacionalismo voraz o se ha obliterado completamente, donde ambas alternativas terminan siendo la misma" (2006: 183). La respuesta al grito de lo humano: la obra de Caparrós no ofrece una respuesta contundente a este problema; incluso en algunas ocasiones resulta complicado distinguir el tratamiento que lleva a cabo en su trabajo del de algunas formas de representación a las que se refiere Butler (quizás el ejemplo más claro lo constituya el descarte de la historia de Koné debido al afán de amplitud que le dicta su colaboración con la $\mathrm{ONU}$ ).

No obstante, hay momentos de Caparrós en los que la representación adquiere otra consistencia gracias al análisis de las lógicas y los marcos que vertebran el sistema de distribución de los recursos. En este punto, quizá como en ningún otro, la inclusión del ensayo le permite encontrar puntos de fuga; las historias personales en las que ha invertido tiempo y espacio a lo largo de la obra espesan el análisis, y lo mismo sucede en la dirección contraria:

Ahora, en un mundo donde las máquinas son tanto más eficaces, la mano de obra y el trabajo - las personas - sobran. Las guerras y las epidemias, que siempre funcionaron como mecanismos de regulación demográfica, bajaron, pese a todo, mucho últimamente. La gente vive más, los chicos mueren menos: somos demasiados. Pero no somos demasiados en abstracto, en general: hay algunos que son demasiados. Es una situación perfectamente anómala: no sé si había pasado alguna vez con esta intensidad, en estas cantidades. A veces pienso que es uno de los grandes cambios de 
la época: por primera vez en la historia, un sexto o un quinto de la población del mundo sobra. Como queda feo que se mueran sin más, los mantienen apenas a flote, desnutridos pero no muertos de hambre (2014: 420).

Aquí es donde se conecta el trabajo ensayístico que recorre la obra de Caparrós con imágenes como la de la mujer de Níger saliendo del hospital y cargando con su bebé muerto, con las historias de migrantes viajando de un país a otro en busca de las condiciones mínimas para ejercer una vida digna o con testimonios como el de Mariama y el plano uniforme en el que se desarrolla una existencia enfocada en la búsqueda de la comida del día. Se trata de segmentos de población (que son al mismo tiempo cuerpos, ${ }^{8}$ afectos, el grito de lo humano) cuya desaparición no provoca ningún tipo de duelo. "¿Cuál es la relación entre la violencia por la que estas vidas que no valen la pena se han perdido y la prohibición de su duelo público? ¿La prohibición del duelo es la continuación de la violencia? ¿Y la prohibición del duelo exige un control más riguroso de la reproducción de imágenes y palabras?", escribe Butler (2006: 184), que a continuación señala que si las humanidades tienen todavía algún futuro como crítica cultural éste consiste en "devolvernos a lo humano allí donde no esperamos hallarlo, en su fragilidad y en el límite de su capacidad para tener algún sentido" (2006: 187).

La continuación de la violencia presente en la representación de esas vidas carentes de duelo se ve truncada por las posibilidades estéticas que ofrece el ensayo puesto en práctica en la obra de Caparrós:

8 Pensarlos en su calidad de cuerpos responde también a la necesidad de establecer una línea de lo que Butler denomina precariedad; es decir, una posición compartida desde la cual nuestra supervivencia "depende de lo que podríamos llamar una red social de manos" (Butler 2010: 31). Esto no evita que, como también señala Butler, las condiciones determinen la existencia de vidas más precarias que otras. Es posible, en consecuencia, entender los cuerpos de otra manera: "Por supuesto, el sistema no se rinde, y de vez en cuando descubre nuevos usos para los desechables: esas clínicas indias que contratan mujeres muy pobres para usarlas como vientres. Madres y padres del mundo rico mandan sus embriones fecundados o sus óvulos y espermas y doctores locales se los implantan a una chica local que, por poner su cuerpo a trabajar full time durante nueve meses, gana lo que no podría ganar en 20 años de trabajo" (Caparrós 2014: 422). 
Se trata de redefinir qué es mortal y qué no: de qué es lícito morirse y de qué no. Todo está ahí: en realidad, el mayor escándalo es esta obviedad de que, cada año, cada mes, cada día, se mueren miles, millones de personas que no deberían morirse o, mejor dicho: que no se morirían de lo que se están muriendo si no vivieran en países pobres, si no fueran tan pobres. Se trata de pensar en el mayor privilegio posible: vivir allá donde otros mueren (2014: 115).

A esto me refería cuando hablaba de aquello que las técnicas del ensayo hacían. Desde esta perspectiva, el cruce entre ensayo y narración abre la oportunidad para el establecimiento de una estética que rompa con la del discurso dominante: como argumentaba Weinberg (Garza 2007: 282), el ensayo cumple con la tarea de dar una resolución estética a problemas éticos.

Retomando el ensayo de Walter Benjamin "La obra de arte en la era de su reproductibilidad técnica", Susan Buck-Morss argumenta que la tarea del arte consiste en "deshacer la alienación del sensorium corporal, restaurar la fuerza instintiva de los sentidos corporales humanos por el bien de la autopreservación de la humanidad y la de hacer todo esto no evitando las nuevas tecnologías sino atravesándolas" (2005: 171). Para Buck-Morss, el discurso estético está intrínsecamente ligado a nuestras capacidades sensoriales, a nuestra capacidad de percepción. Aquí es donde se juntan Buck-Morss, Butler y Caparrós, en la necesidad de sus trabajos de proponer otro régimen de sensibilidad, uno en el que todas las vidas sean representadas en un marco en el que el duelo no les sea negado.

\section{EL ÁRBOL Y LA ONDA}

"Cuando los historiadores analizan la cultura a escala mundial (o al menos a gran escala), tienden a usar dos metáforas cognitivas básicas: el árbol y la onda [...] El árbol describe el pasaje de la unidad a la diversidad; es un solo árbol, con muchas ramas: de la familia indoeuropea a una miríada de lenguas diferentes. La onda es todo lo contrario, ya que describe cómo la 
uniformidad engulle una inicial diversidad" (Moretti 2015: 52). Para Moretti, ambas metáforas funcionan. La historia cultural está hecha de la oscilación entre árboles y ondas.

Este artículo ha intentado avanzar de la misma manera, alternando ambas imágenes. Por un lado, el ensayo como una onda de cierta consistencia uniforme, anclado en sus orígenes franceses y con el problema de fondo del ejercicio de la voz. ¿Quién habla? ¿A través de qué mecanismos ha adquirido la capacidad de ejercer la voz? son preguntas que conviven y enriquecen otros cuestionamientos: ¿qué hace un ensayo?, ¿cuáles son sus capacidades analíticas y expresivas?

El árbol, por su parte, aparece cuando ponemos atención a la manera en que el ensayo entra en contacto con las ramas de los acontecimientos situados en países en permanentes crisis migratorias, climáticas y de hambre. En este intercambio las transformaciones circulan en ambas direcciones. Los afectos personales adquieren una dimensión más amplia cuando se sitúan dentro de la lógica que determina el contexto en que éstos tienen lugar; el ensayo gana en profundidad al movilizar ideas y conceptos a la par de historias personales. En la obra de Caparrós, ensayo y narración funcionan a la par, probando sus límites, poniéndose en tensión.

Esta imbricación resulta oportuna para detallar uno de los temas centrales en el ciclo de obras de Caparrós: la repartición desigual del duelo, cuyo efecto (la falta de reconocimiento de una vida) constituye, de acuerdo con Butler, una extensión de la violencia. Partiendo de esta situación, las obras que se analizan en este trabajo proponen una solución estética a un problema ético. Esa quizá sea el efecto principal que se produce en la mezcla de ensayo y crónica que propone la obra de Caparrós: un cruce que, complejizándolo, abre posibilidades en la representación mediática del dolor y el duelo y que expande las posibilidades analíticas del periodismo en relación con los problemas globales de la actualidad. 
BIBLIOGRAFÍA

ARENDT, HANNAH. Conferencias sobre la filosofía politica de Kant. Barcelona: Paidós, 2003.

AlexiÉvich, SveTlana. Los muchachos del zinc. Barcelona: Debate, 2016.

AtTridge, DereK. J. M. Coetzee and the Ethics of Reading. Chicago: Universidad de Chicago, 2004.

Aullón, PEDRO. "El ensayo y Adorno". 1997. Artículo en línea disponible en https://core.ac.uk/download/pdf/16356637.pdf [consultado el 19 de diciembre de 2019].

BOHM, ARnd. "Coercion to Speak in J. M. Coetzee's Life and Times of Michael K”. 2000. Artículo en línea disponible en https://journals.lib. unb.ca/index.php/IFR/article/view/7656/8713 [consultado el 18 de diciembre de 2019].

BuCK-MORSS, SusAn. Walter Benjamin, escritor revolucionario. Buenos Aires: Interzona Editora, 2005.

BuTLER, JUDITH. Vida precaria. El poder del duelo y la violencia. México: Paidós, 2006.

- Marcos de guerra. Las vidas lloradas. México: Paidós, 2010.

CAPARRós, MARTín. Una luna. Diario de hiperviaje. Barcelona: Anagrama, 2009.

. Contra el cambio. Un hiperviaje al apocalipsis climático. Barcelona: Anagrama, 2010.

. "Por la crónica". Darío Jaramillo (ed.). Antología de crónica latinoamericana actual. México: Alfaguara, 2011.

- El hambre. México: Planeta, 2014.

- "Ser es leerse". 2015. Artículo en línea disponible en https:// elpais.com/cultura/2015/03/23/babelia/1427129925_968384.html [consultado el 13 de noviembre de 2019].

CARRIÓN, JORGE. (2014). "El ensayo será experimental o no será". 2014. Artículo en línea disponible en http://ab.cccb.org/es/el-ensayo-sera-experimental-o-no-sera/ [consultado el 18 de diciembre de 2019]. 
CerutTi, Horacio. "Hipótesis para una teoría del ensayo (primera aproximación)". Carlos Oliva (comp.). La fragmentación del discurso: ensayo y literatura. México: UNAM, 2009.

DABASHI, HAMID. "Fuck you Zizek". 2016. Artículo en línea disponible en https://www.zedbooks.net/blog/posts/fuck-you-zizek/ [consultado el 26 de abril de 2019].

FEDERICI, Silvia. Calibán y la bruja. Mujeres, cuerpo y acumulación originaria. México: Tinta Limón Ediciones, 2005.

GaRZA, NOrMA. (2007). "El ensayo como poética del pensamiento. 2007. Entrevista con Liliana Weinberg". Artículo en línea disponible en http://www.scielo. org.mx/scielo.php?script=sci_arttext\&pid=S1870-00632007000200011 [fecha de consulta: 19 de noviembre de 2019].

GROYS, BORIs. Volverse público. Las transformaciones del arte en el ágora contemporánea. Buenos Aires: Caja Negra Editora, 2015.

MATEO, JosÉ. "Escribir en el margen". 2018. Artículo en línea disponible en http://revistas.unam.mx/index.php/deraizdiversa/article/view/67367 [consultado el 6 de noviembre de 2019].

MoreTti, FranCo. Lectura distante. Buenos Aires: FCE, 2015.

RIVERA, JACINTO. Kant y Hannah Arendt. La comunidad del juicio reflexionante. 2005. Artículo en línea disponible en http://www.scielo. org.co/pdf/idval/v54n128/v54n128a01.pdf [consultado el 14 de agosto de 2019].

SALAZAR, JEZREEL. La crónica: una estética de la transgresión. 2005. http:// www.razonypalabra.org.mx/anteriores/n47/jsalazar.html [fecha de consulta: 20 de diciembre, 2019].

Snoey, Christian. "Una lectura pigliana de la obra de Martín Caparrós". 2016. Artículo en línea disponible en https://digitum.um.es/xmlui/ bitstream/10201/51582/1/Martin\%20Caparros.pdf [consultado el 9 de noviembre, 2019].

WaLsh, Rodolfo. Operación Masacre. Buenos Aires: 451 Editores, 2008. WEINBERG, LIIIANA. El ensayo, entre el paraíso y el infierno. México: FCE, 2001. Situación del ensayo. México: CCyDEL-UnAM, 2006. Pensar el ensayo. México: Siglo xxI, 2007. 